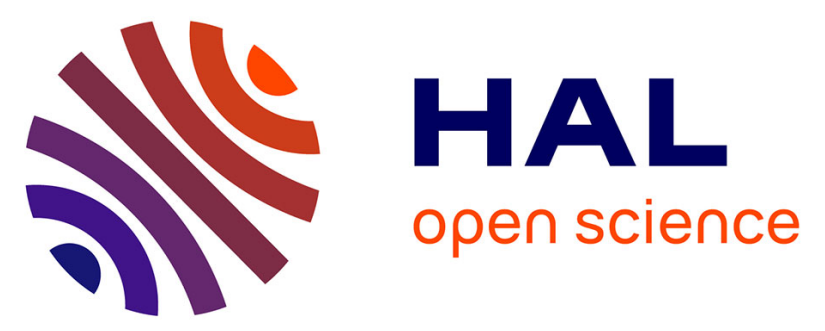

\title{
Coexistence of circulating HBsAg and anti-HBs antibodies in chronic hepatitis $B$ carriers is not a simple analytical artifact and does not influence $\mathrm{HBsAg}$ quantification
}

Marie Pancher, Nathalie Désiré, Yen Ngo, Sepideh Akhavan, Coralie Pallier, Thierry Poynard, Vincent Thibault

\section{To cite this version:}

Marie Pancher, Nathalie Désiré, Yen Ngo, Sepideh Akhavan, Coralie Pallier, et al.. Coexistence of circulating HBsAg and anti-HBs antibodies in chronic hepatitis B carriers is not a simple analytical artifact and does not influence HBsAg quantification. Journal of Clinical Virology, 2015, 62, pp.32-37. 10.1016/j.jcv.2014.11.015 . hal-01102734

\section{HAL Id: hal-01102734 \\ https://hal.sorbonne-universite.fr/hal-01102734}

Submitted on 13 Jan 2015

HAL is a multi-disciplinary open access archive for the deposit and dissemination of scientific research documents, whether they are published or not. The documents may come from teaching and research institutions in France or abroad, or from public or private research centers.
L'archive ouverte pluridisciplinaire HAL, est destinée au dépôt et à la diffusion de documents scientifiques de niveau recherche, publiés ou non, émanant des établissements d'enseignement et de recherche français ou étrangers, des laboratoires publics ou privés. 
Coexistence of circulating HBsAg and anti-HBs antibodies in chronic hepatitis B carriers is not a simple analytical artifact and does not influence HBsAg quantification

Pancher Marie ${ }^{1}$, Désiré Nathalie ${ }^{1,6}$, Ngo Yen $^{2,3}$, Akhavan Sepideh $^{1}$, Pallier Coralie ${ }^{5}$, Poynard Thierry ${ }^{2,3}$, Thibault Vincent ${ }^{\# 1,4}$

1-AP-HP, Pitié-Salpêtrière Hospital, Virology Department, Paris, France

2-AP-HP, Pitié-Salpêtrière Hospital, Service d'Hépato-Gastro-Entérologie, Paris,

France

3-Sorbonne Universités, UPMC Univ Paris 06, UMR 8149, F-75005, Paris, France

4-Inserm U1135, F-75013, Paris, France

5-AP-HP, Paul Brousse Hospital, Virology, Villejuif, France

Running title: HBsAg quantification in anti-HBs positive HBV carriers

Abstract word count: 250

Text word count: 2498

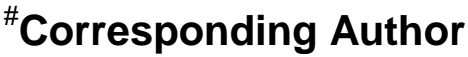 \\ Dr Vincent THIBAULT \\ Virology Dept - CERVI \\ Hôpitaux Universitaires La Pitié Salpêtrière - Charles Foix \\ 83 Bd De l'Hôpital \\ 75651 PARIS Cedex 13 \\ FRANCE \\ Tel: +33 -1 42177401 \\ Fax: +33 -1 42177411 \\ vincent.thibault@psl.aphp.fr
}




\section{Abstract}

Background Presence at the same time of HBsAg and anti-HBs antibodies ( $\mathrm{HBsAg} / \mathrm{Ab}$ ) is an entity sometimes encountered in chronic hepatitis B $(\mathrm{CHB})$ carriers.

Objectives This study was designed to characterize such serological profiles and to assess the reliability of serological marker quantification by three commercially available assays in this setting.

Study design Among 2578 CHB identified patients, 129 (5\%) had an HBsAg/Ab profile as determined by Abbott Architect. After exclusion of co-infections (HIV, HCV, HDV), HBV reactivation or HBIg treatment, 101 samples from 62 patients were tested for HBsAg and anti-HBs quantification using Architect, DiaSorin Liaison-XL and Roche Modular-Cobas. Influence of genotype and HBsAg variants was studied in 31 samples with HBV replication.

Results HBsAg detection was confirmed with the 3 techniques for $98 \%(n=99)$ of the samples while the HBsAg/Ab profile was concordant between all techniques for $65 \%$ of them. The overall correlation between the 3 HBsAg quantification techniques was good $\left(r^{2}: 0.94-0.97\right)$. The median HBsAg concentration was comparable for the 99 samples whatever the used technique but a bias of -0.11 and $0.02 \log \mathrm{IU} / \mathrm{mL}$ were noticed for DiaSorin and Roche compared to Abbott, respectively. Anti-HBs quantifications were poorly correlated between techniques with major discrepancies observed. Genotype and substitutions within the "a" determinant showed an impact on HBsAg quantification.

Conclusions The double HBsAg/Ab profile is not an analytical artifact and is confirmed on all commercially available techniques. While such profile does not influence HBsAg quantification, differences of HBsAg quantification were noticed according to HBV genotype or HBsAg variant.

Keywords: HBsAg quantification - HBsAg variant - Genotype - immune complexes - interference 


\section{Highlights}

- $\quad \mathrm{HBsAg}$ and anti-HBs double positive serological profile is found in $5 \%$ of $\mathrm{CHB}$

- Concomitant detection of both markers is confirmed by 3 assays in $65 \%$ of the cases

- HBsAg quantification is not affected by the presence of detectable anti-HBs

- HBsAg quantification varies according to the assay, the genotype and Ag substitutions 


\section{Background}

HBsAg is a key marker for the diagnosis of acute or chronic HBV infection. Available qualitative or quantitative assays detect all circulating HBsAg containing particles, mainly infectious virions (Dane particles) but in a large excess non infectious/defective particles (1). While chronic infection is defined by the persistence of HBsAg over 6 months, HBsAg loss and appearance of anti-HBs Ab (anti-HBs) usually sign viral clearance. Yet, occurrence of anti-HBs is sometimes observed despite persistence of HBsAg and viral replication. The prevalence of this entity has been reported in less than $5 \%$ to more than $25 \%$ of $\mathrm{CHB}$ cases, depending on the studies (2-5).

The molecular and immunologic mechanisms leading to this serologic profile remain unclear but could be due to the selection of HBV escape mutants by immune pressure (6-8). In this scenario, the detected circulating antibodies are directed against an HBV strain not present anymore. Indeed, several reports have shown an association of this pattern with an increased proportion of HBsAg mutants characterized by specific substitution or deletion in the preS/S gene, especially in the "a" determinant region. Amino acid substitutions within this epitope could modify the antigenic conformation of HBsAg and alter the binding of both monoclonal and polyclonal anti-HBs antibodies; the main consequences being the emergence of an immune escape variant and an alteration of HBsAg detection assay (3,4,9-13).

Most recently, the amount of circulating HBsAg has been recognized as a potential biomarker linked to the liver disease stage, the risk of HCC or the chance to respond to interferon therapy (14-17). Beside the most widely used Architect assay (Abbott), two other CE marked assays are also available for the quantification of HBsAg, the Elecsys platform (Roche) and the Liaison-XL from DiaSorin. These assays use both mononoclonal and/or polyclonal antibodies to enhance recognition of HBsAg and HBsAg mutants. Several studies have convincingly demonstrated the comparable performances of Roche and Abbott assays (18-20). More recently, the DiaSorin assay was shown to perform comparably to the Architect assay in sequential serum samples from $14 \mathrm{HBe}$-negative patients (21).

\section{Objectives}

The aims of our study were first to document the performances of the DiaSorin assay compared to our routine Abbott's Architect HBsAg quantification. Secondly, the robustness of HBsAg quantification using the three CE marked available assays on a panel of CHB seras containing both HBsAg and anti- 
HBs was challenged. One main issue was to determine whether concomitant detection of both HBsAg/anti-HBs could solely be an analytical artifact linked to a specific assay. Likewise, a further goal was to assess the ability of these assays to quantify potential variants more prone to be selected in these peculiar serological profiles.

\section{Study design}

\section{Patients and sera}

In the first part of the study comparing Abbott and DiaSorin on HBsAg positive samples, 227 sera successively tested for HBsAg quantification between September and November 2012 on Architect (Abbott, Rungis, France) were tested on DiaSorin Liaison-XL (Antony, France).

One hundred and one sera corresponding to $62 \mathrm{CHB}$ patients identified HBsAg/anti-HBs positive on Architect between January 2008 and June 2012 and stored at $-20^{\circ} \mathrm{C}$ were selected. Exclusion criteria were any HIV, hepatitis C or hepatitis D coinfection, HBIg passive immunization or reactivation of past HBV infection. All sera were subsequently tested for HBsAg and anti-HBs on the Roche Elecsys system (Meylan, France) and DiaSorin Liaison-XL, according to each manufacturer's recommendation. The measurements were performed within 5 days on all systems.

Among the 62 selected patients, 31 had also an HBV viral load above $100 \mathrm{IU} / \mathrm{mL}$ on the same day as HBsAg quantification and sequencing of the HBsAg gene could be performed on $-80^{\circ} \mathrm{C}$ stored plasma.

Unless specified, HBsAg quantification was reported in $\log _{10} \mathrm{IU} / \mathrm{mL}$ and anti-HBs in IU/L. The study general outline is presented on figure 1.

HBsAg gene sequencing method

HBV-DNA was purified from $500 \mu \mathrm{L}$ of plasma using Nuclisens EasyMAG (Biomérieux, Marcilly, France) and resuspended in $70 \mu \mathrm{L}$ of sterile water. Amplification of part of the HBsAg coding region (nt. 186-1196, aa 100-227) was performed as previously described (4). Sequences were aligned and compared to selected Genbank reference sequences of known genotype using SeqScape (Applied Biosytems) and Mega (v5) softwares (22). For analysis purpose, HBsAg was divided into 3 regions: residues 100-123, 124-147 ("a" determinant) and 148-221. Substitutions were determined manually and with the help of two online tools (http://hbv.bioinf.mpi-inf.mpg.de/ and http://www.hiv-grade.de).

Statistical analysis 
Statistical analysis, were performed using Analyze-it software. Chisquare and Fischer tests were used for categorical variables. Mean and medians were analyzed with Mann Whitney and Kruskal tests. Bland-Altman analysis was used to compare methods. Significance was defined by a $\mathrm{P}$ value below 0.05

\section{Results}

Overall performances of Liaison-XL HBsAg quantification on 227 HBsAg positive samples

On these 227 samples, there was a strong correlation $(p<0.001)$ between both Abbott and DiaSorin systems with an $r^{2}$ of 0.96 (fig. $2 A$ ) despite a mean quantification difference of $-0.16 \log _{10} \mathrm{IU} / \mathrm{mL}(95 \%$ $\mathrm{Cl}:-0.19 ;-0.14)$ throughout the quantification range (fig. $2 \mathrm{~B}$ ). The results provided by the Liaison-XL were constantly and significantly lower than those by the Architect assay $(p=0.04)$.

\section{Characteristics of patients carrying both HBSAg and anti-HBs}

Among 2578 chronic HBsAg carriers followed between 2008 and 2012, 129 (5\%) patients were concomitantly HBsAg/anti-HBs positive and 62 (2.4\%) were included in the study (fig. 1). Except from above mentioned inclusion criteria, available stored sample volume also restricted inclusion into the study. The main characteristics of the patients selected for the principal and molecular studies are summarized in table 1. Noteworthy, most of the samples had an anti-HBs concentration lower than 50 IU/L (median: $24 \mathrm{IU} / \mathrm{L}$ ) but 31 (30.7\%) and 14 (13.9\%) had values above 50 and $100 \mathrm{IU} / \mathrm{L}$, respectively. No correlation was found between the concentration of HBsAg and anti-HBs (data not shown). The median viral load of the patients selected for S-gene sequencing was $3.6 \log \mathrm{IU} / \mathrm{mL}$; the best performance for sequencing being usually obtained above $1000 \mathrm{IU} / \mathrm{mL}$.

Qualitative analysis of the HBsAg results obtained with the three assays

Concurrent HBsAg and anti-HBs reactivity was confirmed unequivocally with the three techniques for $65 \%$ of the 101 samples (table 2). The concordance between all techniques was better for HBsAg than for anti-HBs. Noteworthy, the median anti-HBs values obtained with Abbott for concordant (32.5 IU/L; IQR 69.4) versus discordant (19 IU/L; IQR 21.8) results were statistically different ( $p=0.01)$.

The HBsAg discordant samples ( 1 for DiaSorin and 2 for Roche) belong to the same patient who was followed at several visits and had persistently very low HBsAg levels: 0.07 and $0.05 \mathrm{IU} / \mathrm{mL}$ on 
Architect (table 3). Noteworthy, a third sample with a value of $0.1 \mathrm{IU} / \mathrm{mL}$ with Abbott was correctly detected with Roche and DiaSorin, respectively at $0.041 \mathrm{UI} / \mathrm{mL}$ and $0.057 \mathrm{IU} / \mathrm{mL}$.

Quantitative analysis of HBsAg results obtained with the three assays

All HBsAg positive data for HBsAg/anti-HBs samples were considered in the quantitative assessment of these assays.

The overall correlation of all assays was satisfactory with $r^{2}$ ranging from 0.93 for DiaSorin $(n=100)$ and Roche ( $\mathrm{n}=99$ ) to 0.97 for Abbott and Roche assays (fig. 3). The best concordance was obtained between Roche and Abbott with a mean bias of $0.022 \log \mathrm{IU} / \mathrm{mL}(95 \% \mathrm{Cl}:-0.024$ to 0.067$)$ in favor of Roche while the most divergent quantification was observed between DiaSorin and Roche (bias of $0.130 \log \mathrm{IU} / \mathrm{mL}$ in favor of Roche with $95 \% \mathrm{Cl}$ from 0.048 to 0.212 ). The mean bias between Architect and Liaison-XL was $-0.113 \log \mathrm{IU} / \mathrm{mL}$; the lower values being reported by DiaSorin. A comparison of the biases was performed between samples concordant for the detection of both $\mathrm{Ag}$ and $\mathrm{Ab}$ on all techniques $(n=66)$ to the discordant ones $(n=33)$; no statistically significant difference was observed according to the discordant status.

Quantitative analysis of the results obtained with the three assays for anti-HBs antibodies

To limit any bias, only samples reactive (anti-HBs $>10 \mathrm{IU} / \mathrm{L})$ with the three techniques $(n=68)$ were taken into consideration for this analysis. Each technique value was compared to the obtained mean value on the three techniques. The best correlation was obtained with DiaSorin assay $(R 2=0.81)$. The mean differences $(95 \% \mathrm{Cl})$ to the mean for Abbott, DiaSorin and Roche were, -18.9 (-31 to -6.8$) ; 21.2$ (8.4 to 33.9) and -2.30 (-12.1 to 7.5$)$ IU/L, respectively (data not shown).

Variability of HBsAg quantification according to genotypic features

Thirty one samples could be sequenced for genotype determination and HBsAg substitution analysis (table 1). Ten genotype C, 8 D, 7 E, 4 B, and 1 each genotype $A$ and F were detected. To compare HBsAg quantification between all techniques, the mean value obtained by the 3 techniques for each sample was calculated. Then, the percentage of HBsAg quantification over the mean was calculated for each technique and analyzed according to the genotype or the presence of substitution. 
Sequence analyses showed that $77 \%$ (24/31 cases) of the HBsAg/anti-HBs samples harbored amino acid substitutions on residues 100-221. Substitutions previously described to modify HBsAg antigenicity were closely examined (23). Forty five percent $(n=14)$ of the strains had such substitutions, with the following amino-acid changes: sT126I $(n=3)$, sQ129G $(n=1)$, SG130N $(n=1)$, sN131H ( $n=1)$, sF134S ( $n=1)$, sC137S $(n=1), \operatorname{sS143L}(n=3), \operatorname{sG145R}(n=2)$ (table 4). The most described sG145R substitution was detected in 2 cases (6\%). All but one genotype D strains carried S substitution, while only $3(30 \%)$ variants were found among the 10 genotype C strains.

Quantification differences between the three assays according to genotype and "a" determinant substitutions were specifically analyzed on the three systems (figure 4 and 5). Although the size of our population was limited, we found a slight influence of HBV genotype on HBV quantification whatever the considered technique. Regarding the "a" determinant substitutions, Roche and DiaSorin techniques seemed to be the most affected. Noteworthy, all variants were correctly detected but DiaSorin tended to underestimate the variant concentration while Roche gave higher than expected values.

\section{DISCUSSION}

HBsAg concentration measurement has become a clinically relevant marker in addition to the well standardized panel of serological and molecular markers. As for HBV viral load, standardization of both the measurement unit and the techniques is mandatory to provide clinicians with comparable quantitative HBsAg values whatever the utilized method. Both Roche and Abbott HBsAg quantification techniques have been extensively studied with the conclusion that both techniques are overall very comparable and can be used indifferently to monitor patients $(18,19,24)$. By contrast, the newest DiaSorin assay has only been studied in two small studies comparing its performance to the Abbott system $(21,25)$. Our study first confirms these previous results and indicates that the Architect values are always $0.16 \log \mathrm{IU} / \mathrm{mL}$ higher than those from the Liaison-XL. From all published studies, one may conclude that a patient could be followed indifferently with Abbott or Roche assay but an adjustment may be required if the Liaison- $X L$ is used during follow up.

Simultaneous detection of both $\mathrm{HBs} \mathrm{Ag}$ and $\mathrm{Ab}$ is often puzzling in clinical situations. Indeed, although this peculiar profile has been described by several authors in different settings, one may wonder whether it corresponds to a true analytical observation (3-5,26-29). Overall, we show that the 
qualitative agreement is $65 \%$ for the coexistence of both $\mathrm{Ag}$ and $\mathrm{Ab}$, providing a strong argument that these detections are not a simple artifact. These data are comparable to the $78.6 \%$ concordance rate reported in a small study using only two first generation qualitative assays (30). Each of these techniques uses different combination of $\mathrm{Ag}$ and antibodies in different format and confirmation by three independent techniques is reassuring. According to our experience, Ag/Ab samples may sometimes pose problem when performing an HBsAg neutralization assay as proposed by manufacturers. One should stress that a thorough selection was performed in our population to not include clinical situations where such profiles may simply be a consequence of therapeutic interventions. Indeed, coexistence of both $\mathrm{Ag}$ and $\mathrm{Ab}$ markers is common during HBV reactivation (occurrence of HBsAg in a patient with resolved HBV infection) or administration of immunoglobulins; in these settings coexistence of both markers are usually only transient. In our set of samples, the agreement for anti-HBs detection screened by Abbott, is not as convincing as for HBsAg but reach $86 \%$ and $71 \%$ with DiaSorin and Roche assays, respectively. In terms of correlation between anti-HBs measurement, the results are concordant with what observed on classical samples, anti-HBs positive but HBsAg negative (31). Taking into account the mean of the three techniques for anti-HBs determination, it should be pointed out that $15.8 \%(n=16)$ samples were above $100 \mathrm{IU} / \mathrm{L}$, a threshold often considered as highly protective in exposed persons. Yet, it emphasizes the risk of considering someone protected against HBV infection if anti-HBs are solely looked for in a screening program; obviously, anti-HBs should not be used as a single screening test as it may falsely misdiagnose a vaccine status in a patient with an active HBV infection! (32)

Correlations between HBsAg measurement assays were very satisfactory even in these peculiar sera where anti-HBs could potentially interfere with measurement (fig. 3). Astonishingly, all assays showed performances very similar to what observed in classical HBsAg positive samples by us and others $(18,21,24,25,33)$. The concordance for HBsAg detection was also very strong and only 2 samples at the limit of detection by all techniques were not detected on the Elecsys. The above conclusions, regarding the lower values obtained on the Liaison- $\mathrm{XL}$, were still valid on these $\mathrm{Ag} / \mathrm{Ab}$ positive samples. One rationale for testing such $\mathrm{Ag} / \mathrm{Ab}$ samples was the likelihood to artificially enrich our set with HBsAg variants $(7,34)$. Actually, variant strains were detected in $77 \%(24 / 31)$ of the samples and $45 \%(14 / 31)$ of the substitutions could potentially modify HBsAg antigenicity (23). Although our study was not primarily designed to demonstrate an influence of HBV genotype on HBsAg quantification and 
the tested numbers are rather limited, some unexpected differences between techniques for the most represented genotypes, B, C, D and E were observed. This observation is currently being further documented in a collaborative study on more samples. Many studies have shown that "a" determinant variants were incorrectly detected or quantified by commercially available assays in the past (13). The attractive strategy of protein unfolding proposed by DiaSorin did not seem to significantly enhance the detection of variants and the Architect system was the less affected by the substitutions present on our samples (fig. 5) (25). Noteworthy, the 2 samples carrying the sG145R variant were quantified to the same level by all three techniques. Overall, it was not possible to identify a specific protein pattern that would particularly affect one technique and the most divergent results were not specifically observed for HBsAg variants.

In summary, this study demonstrates the overall good performance of quantitative assays for HBsAg even in patients with coexisting HBs and anti-HBs. Although, the precise reasons for this entity remain elusive, confirmation on three techniques tend to prove that a technical artifact is not to be blamed in the majority of the cases. The difference observed between techniques should remind us that sequential monitoring should ideally be performed with a unique assay even though all techniques provide well correlated quantification. 
Funding: Reagents and technical support were kindly provided by DiaSorin for the Liaison-XL and Roche for the Elecsys.

Competing interests: All authors but VT declare to have no conflict of interest in the presented work. VT declares to have received speaker fees and travel support from Abbott, DiaSorin and Roche.

Ethical approval: this non interventional study has been performed according to the national current health regulations and in accordance with the ethics principles of the Declaration of Helsinki.

Acknowledgements: Authors are grateful to Odile Pertrizeard, Lydie Postic, Hélène TsyrinaKouyoumdjian and Raphael Crosnier for their excellent technical expertise. 


\section{Bibliography}

1. Seeger C, Mason WS. Hepatitis B virus biology. Microbiol Mol Biol Rev. 2000 Mar;64(1):51-68.

2. Liu W, Hu T, Wang X, Chen Y, Huang M, Yuan C, et al. Coexistence of hepatitis B surface antigen and anti-HBs in Chinese chronic hepatitis $B$ virus patients relating to genotype $C$ and mutations in the S and P gene reverse transcriptase region. Arch Virol. 2012 Apr;157(4):627-34.

3. Zhang J-M, Xu Y, Wang X-Y, Yin Y-K, Wu X-H, Weng X-H, et al. Coexistence of hepatitis $B$ surface antigen (HBsAg) and heterologous subtype-specific antibodies to HBsAg among patients with chronic hepatitis B virus infection. Clin Infect Dis. 2007 May 1;44(9):1161-9.

4. Lada O, Benhamou Y, Poynard T, Thibault V. Coexistence of hepatitis B surface antigen (HBs $\mathrm{Ag}$ ) and anti-HBs antibodies in chronic hepatitis B virus carriers: influence of "a" determinant variants. J Virol. 2006 Mar;80(6):2968-75.

5. Colson P, Borentain P, Motte A, Henry M, Moal V, Botta-Fridlund D, et al. Clinical and virological significance of the co-existence of HBsAg and anti-HBs antibodies in hepatitis B chronic carriers. Virology. 2007 Oct 10;367(1):30-40.

6. Pondé R a. A. The underlying mechanisms for the "simultaneous HBsAg and anti-HBs serological profile." Eur J Clin Microbiol Infect Dis. 2011 Nov;30(11):1325-40.

7. Gerlich WH. The enigma of concurrent hepatitis B surface antigen (HBsAg) and antibodies to HBsAg. Clin Infect Dis. 2007 May 1;44(9):1170-2.

8. Dienstag JL. Concurrent hepatitis B surface antigen and antibody and the clonal selection theory of antibody diversity. Gastroenterology. 1987 Oct;93(4):899-902.

9. Kohno $\mathrm{H}$, Inoue $\mathrm{T}$, Tsuda $\mathrm{F}$, Okamoto $\mathrm{H}$, Akahane $\mathrm{Y}$. Mutations in the envelope gene of hepatitis $B$ virus variants co-occurring with antibody to surface antigen in sera from patients with chronic hepatitis B. J Gen Virol. 1996 Aug;77 ( Pt 8):1825-31.

10. Huang $X$, Qin $Y$, Zhang $P$, Tang $G$, Shi Q, Xu J, et al. PreS deletion mutations of hepatitis $B$ virus in chronically infected patients with simultaneous seropositivity for hepatitis-B surface antigen and anti-HBS antibodies. J Med Virol. 2010 Jan;82(1):23-31.

11. Chen Y, Qian F, Yuan Q, Li X, Wu W, Guo X, et al. Mutations in hepatitis B virus DNA from patients with coexisting HBsAg and anti-HBs. J Clin Virol. 2011 Nov;52(3):198-203.

12. Weber B. Genetic variability of the $\mathrm{S}$ gene of hepatitis B virus: clinical and diagnostic impact. J Clin Virol. 2005 Feb;32(2):102-12.

13. Servant-Delmas A, Mercier-Darty M, Ly TD, Wind F, Alloui C, Sureau C, et al. Variable capacity of 13 hepatitis B virus surface antigen assays for the detection of HBsAg mutants in blood samples. J Clin Virol. 2012 Apr;53(4):338-45.

14. Nguyen T, Thompson AJV, Bowden S, Croagh C, Bell S, Desmond PV, et al. Hepatitis B surface antigen levels during the natural history of chronic hepatitis B: a perspective on Asia. J Hepatol. 2010 Apr;52(4):508-13.

15. Jaroszewicz J, Calle Serrano B, Wursthorn K, Deterding K, Schlue J, Raupach R, et al. Hepatitis $B$ surface antigen (HBsAg) levels in the natural history of hepatitis B virus (HBV)-infection: a European perspective. J Hepatol. 2010 Apr;52(4):514-22.

16. Martinot-Peignoux M, Lapalus M, Laouénan C, Lada O, Netto-Cardoso ACF, Boyer N, et al. Prediction of disease reactivation in asymptomatic hepatitis $B$ e antigen-negative chronic hepatitis B patients using baseline serum measurements of HBsAg and HBV-DNA. J Clin Virol. 2013 Oct;58(2):401-7. 
17. Tseng T-C, Liu C-J, Yang H-C, Su T-H, Wang C-C, Chen C-L, et al. Serum hepatitis B surface antigen levels help predict disease progression in patients with low hepatitis B virus loads. Hepatology. 2013 Feb;57(2):441-50.

18. Wursthorn K, Jaroszewicz J, Zacher BJ, Darnedde M, Raupach R, Mederacke I, et al. Correlation between the Elecsys HBsAg II assay and the Architect assay for the quantification of hepatitis B surface antigen (HBsAg) in the serum. J Clin Virol. 2011 Apr;50(4):292-6.

19. Sonneveld MJ, Rijckborst V, Boucher CAB, Zwang L, Beersma MFC, Hansen BE, et al. A comparison of two assays for quantification of Hepatitis $B$ surface Antigen in patients with chronic hepatitis B. J Clin Virol. 2011 Jul;51(3):175-8.

20. Maylin S, Boyd A, Martinot-Peignoux M, Delaugerre C, Bagnard G, Lapalus M, et al. Quantification of hepatitis B e antigen between Elecsys HBeAg and Architect HBeAg assays among patients infected with hepatitis B virus. J Clin Virol. 2013 Apr;56(4):306-11.

21. Burdino E, Ruggiero T, Proietti A, Milia MG, Olivero A, Caviglia GP, et al. Quantification of hepatitis B surface antigen with the novel DiaSorin LIAISON XL Murex HBsAg Quant: Correlation with the ARCHITECT quantitative assays. J Clin Virol. 2014 Aug;60(4):341-6.

22. Tamura K, Peterson D, Peterson N, Stecher G, Nei M, Kumar S. MEGA5: molecular evolutionary genetics analysis using maximum likelihood, evolutionary distance, and maximum parsimony methods. Mol Biol Evol. 2011 Oct;28(10):2731-9.

23. Zaaijer $\mathrm{HL}$, Bouter $\mathrm{S}$, Boot $\mathrm{HJ}$. Substitution rate of the hepatitis $B$ virus surface gene. $\mathrm{J}$ Viral Hepat. 2008 Apr;15(4):239-45.

24. Maylin S, Boyd A, Delaugerre C, Zoulim F, Lavocat F, Simon F, et al. Comparison between Elecsys HBsAg II and Architect HBsAg QT Assays for Quantification of Hepatitis B Surface Antigen among Patients Coinfected with HIV and Hepatitis B Virus. Clinical and Vaccine Immunology. 2011 Dec 21;19(2):242-8.

25. Krawczyk A, Hintze C, Ackermann J, Goitowski B, Trippler M, Grüner N, et al. Clinical performance of the novel DiaSorin LIAISON(®) XL murex: HBsAg Quant, HCV-Ab, HIV-Ab/Ag assays. J Clin Virol. 2014 Jan;59(1):44-9.

26. Tabor E, Gerety RJ, Smallwood LA, Barker LF. Coincident hepatitis B surface antigen and antibodies of different subtypes in human serum. J Immunol. 1977 Jan;118(1):369-70.

27. Shiels MT, Taswell HF, Czaja AJ, Nelson C, Swenke P. Frequency and significance of concurrent hepatitis B surface antigen and antibody in acute and chronic hepatitis B. Gastroenterology. 1987 Oct;93(4):675-80.

28. Yamamoto K, Horikita M, Tsuda F, Itoh K, Akahane Y, Yotsumoto S, et al. Naturally occurring escape mutants of hepatitis $B$ virus with various mutations in the $S$ gene in carriers seropositive for antibody to hepatitis B surface antigen. J Virol. 1994 Apr;68(4):2671-6.

29. Zhang Z-H, Li L, Zhao X-P, Glebe D, Bremer CM, Zhang Z-M, et al. Elimination of hepatitis B virus surface antigen and appearance of neutralizing antibodies in chronically infected patients without viral clearance. J Viral Hepat. 2011 Jun;18(6):424-33.

30. Cheng L, Guan Q, Zhang J, Sun Z. Discrepancies between two automated immunoassay systems in determining hepatitis $B$ virus markers in serum samples with concomitant presence of antigens and antibodies. Ann Clin Lab Sci. 2010;40(1):49-52.

31. Kinn S, Akhavan S, Agut H, Thibault V. Performance of the DiaSorin LIAISON( $\left({ }^{\circ}\right)$ anti-HBs II for the detection of hepatitis B surface antibodies: comparison with the Abbott Architect anti-HBs assay. J Clin Virol. 2011 Apr;50(4):297-302. 
32. Advisory Committee on Immunization Practices, Centers for Disease Control and Prevention (CDC). Immunization of health-care personnel: recommendations of the Advisory Committee on Immunization Practices (ACIP). MMWR Recomm Rep. 2011 Nov 25;60(RR-7):1-45.

33. Verheyen J, Neumann-Fraune M, Berg T, Kaiser R, Obermeier M. The detection of HBsAg mutants expressed in vitro using two different quantitative HBsAg assays. J Clin Virol. 2012 Jul;54(3):279-81.

34. Brunetto MR. Chance and necessity of simultaneous HBsAg and anti-HBs detection in the serum of chronic HBsAg carriers. J Hepatol. 2014 Mar;60(3):473-5. 


\section{Figure legends}

Figure 1: General outline of the study

Figure 2: Correlation between HBsAg quantification using Abbott and DiaSorin assays $(n=227)(A)$ and Bland Altman representation (B). The mean bias between both techniques was $-0.162 \log \mathrm{IU} / \mathrm{mL}$.

Figure 3: Correlation between the mean HBsAg values obtained by the three techniques ( $x$ axis) and values obtained by each technique (y axis) on 99 samples detected by all techniques. Abbott: closed circles, plain line $\left(y=0.9724 x+0.0361, R^{2}=0.9877\right)$; DiaSorin: open squares, interrupted line $(y=$ $\left.1.0457 x-0.2432, R^{2}=0.9576\right) ;$ Roche: closed triangles, dotted line: $\left(y=1.0042 x-0.0031, R^{2}=\right.$ $0.9801)$

Figure 4: Box plot representation of HBsAg quantification difference according to HBV genotype. $\mathrm{HBsAg}$ values expressed as $\mathrm{IU} / \mathrm{mL}$ were expressed as a percentage to the mean values obtained with the 3 assays and grouped according to the genotype $B(n=4), C(n=10), D(n=8)$ and $E(n=7)$. Statistically significant differences according to genotype are indicated for each assay.

Figure 5: Box plot representation of HBsAg quantification difference according to the presence of "a" determinant substitution. HBsAg values expressed as $\mathrm{IU} / \mathrm{mL}$ were expressed as a percentage to the mean values obtained with the 3 assays and grouped according to the presence $(Y, n=11)$ or absence $(\mathrm{N}, \mathrm{n}=20)$, of "a" substitution. Statistically significant differences according to "a" substitution are indicated for each assay. 
Table 1: Studied population main characteristics

\begin{tabular}{lcc} 
Parameters: median (range) & Main cohort & $\begin{array}{c}\text { Molecular study } \\
\text { selected patients }\end{array}$ \\
\hline Sex ratio M/F & $37 / 25$ & $18 / 13$ \\
Age $(\mathrm{y})$ & 44.9 & 45.2 \\
HBsAg Abbott $(\mathrm{IU} / \mathrm{mL})$ & $(22.1-79.6)$ & $(22.1-72.2)$ \\
& 556 & 1545 \\
Anti-HBs Ab Abbott IU/mL & $(0.1-233185)$ & $(4.7-233185)$ \\
& 24 & 22 \\
& $(11-257)$ & $(11-115)$
\end{tabular}

Table 2: qualitative agreement between all techniques $(n=101)$

\begin{tabular}{lccc} 
Abbott Reactivity & DiaSorin & Roche & $\begin{array}{c}\text { DiaSorin and } \\
\text { Roche agreement }\end{array}$ \\
\hline HBsAg & $100(99 \%)$ & $99(98 \%)$ & $99(98 \%)$ \\
Anti-HBs & $87(86 \%)$ & $72(71 \%)$ & $68(67 \%)$ \\
Ag/ Ab & $86(85 \%)$ & $70(69 \%)$ & $66(65 \%)$
\end{tabular}

Table 3: Main results for the two HBsAg discrepant samples (samples below detection limit are underlined)

\begin{tabular}{ccccc} 
Sample & Marker & Abbott & DiaSorin & Roche \\
\hline $\mathbf{8 2}$ & HBsAg (IU/mL) & 0.07 & 0.032 & $\leq 0.05$ \\
& Anti-HBs (IU/L) & 21 & 41 & 32 \\
$\mathbf{9 1}$ & HBsAg (IU/mL) & 0.05 & $\leq 0.030$ & $\leq 0.05$ \\
& Anti-HBs (IU/L) & 32 & 57 & 61
\end{tabular}


Table 4: Main substitutions known to influence HBsAg antigenicity detected on each strain

HBsAg residues

\begin{tabular}{|c|c|c|c|c|c|c|c|c|c|c|c|c|c|c|c|c|c|}
\hline NUM & GENOTYPE & P111 & G112 & $\mathrm{S} 117$ & T118 & P120 & T123 & T125 & T126 & P127 & Q129 & G130 & T131 & F134 & C137 & S143 & G145 \\
\hline 90 & $A$ & $T$ & & & & & & & & & $G$ & $\mathrm{~N}$ & $\mathrm{H}$ & & & & \\
\hline 33 & B & & & & & & & & & $\mathrm{T}$ & & & & & & & \\
\hline 37 & B & & & & & & & & & & & & & & & & \\
\hline 81 & $B$ & & & & & & & & & & & & & & & & \\
\hline 85 & B & & & & & & & & & & & & & & & & \\
\hline 1 & C & & & & & & & & & & & & & & & & $\mathrm{R}$ \\
\hline 4 & $\mathrm{C}$ & & & & & & & & & & & & & & & & \\
\hline 5 & C & & & & & & & & & & & & & & & & \\
\hline 6 & $\mathrm{C}$ & & & & & & & & & & & & & & & & \\
\hline 29 & $\mathrm{C}$ & & & & & & & & I & & & & & & & & \\
\hline 41 & $\mathrm{C}$ & & & & & & & & & & & & & & & & \\
\hline 47 & C & & & & & & & & & & & & & & & & \\
\hline 51 & $\mathrm{C}$ & & & & & & & & I & & & & & & & & \\
\hline 61 & $\mathrm{C}$ & & & & & & & & & & & & & & & & \\
\hline 130 & $\mathrm{C}$ & & & & & & & & I & & & & & & & & \\
\hline 24 & D & & & & & & & $M$ & & $\mathrm{~T}$ & & & & & & L & \\
\hline 27 & D & & & & A & & & & & $\mathrm{T}$ & & & & & & & \\
\hline 40 & D & & & & & & & & & & & & & & & & \\
\hline 43 & $\mathrm{D}$ & & & & & & & & & $\mathrm{T}$ & & & & $\mathrm{S}$ & & & \\
\hline 48 & D & & & $\mathrm{N}$ & & & & & & & & & & & S & L & \\
\hline 101 & $\mathrm{D}$ & & $\mathrm{R}$ & & & & $\mathrm{N}$ & & & & & & & & & & \\
\hline 115 & $\mathrm{D}$ & & & & & & & & & & & & & & & & \\
\hline 129 & D & & & & & & & & & & & & & & & L & \\
\hline 8 & $E$ & & & & & & & & & L & & & & & & & \\
\hline 17 & $\mathrm{E}$ & & & & & & & & & & & & & & & & \\
\hline 22 & $\mathrm{E}$ & & & & & & & & & L & & & & & & & $R$ \\
\hline 32 & E & & & & & & & & & L & & & & & & & \\
\hline 50 & $\mathrm{E}$ & & & & & & & & & L & & & & & & & \\
\hline 52 & $\mathrm{E}$ & & & & & & & & & $\mathrm{L}$ & & & & & & & \\
\hline 59 & E & & & & & & & & & L & & & & & & & \\
\hline 15 & $\mathrm{~F}$ & & & & & $\mathrm{Q}$ & & & & L & & & & & & & \\
\hline
\end{tabular}


Figure 1

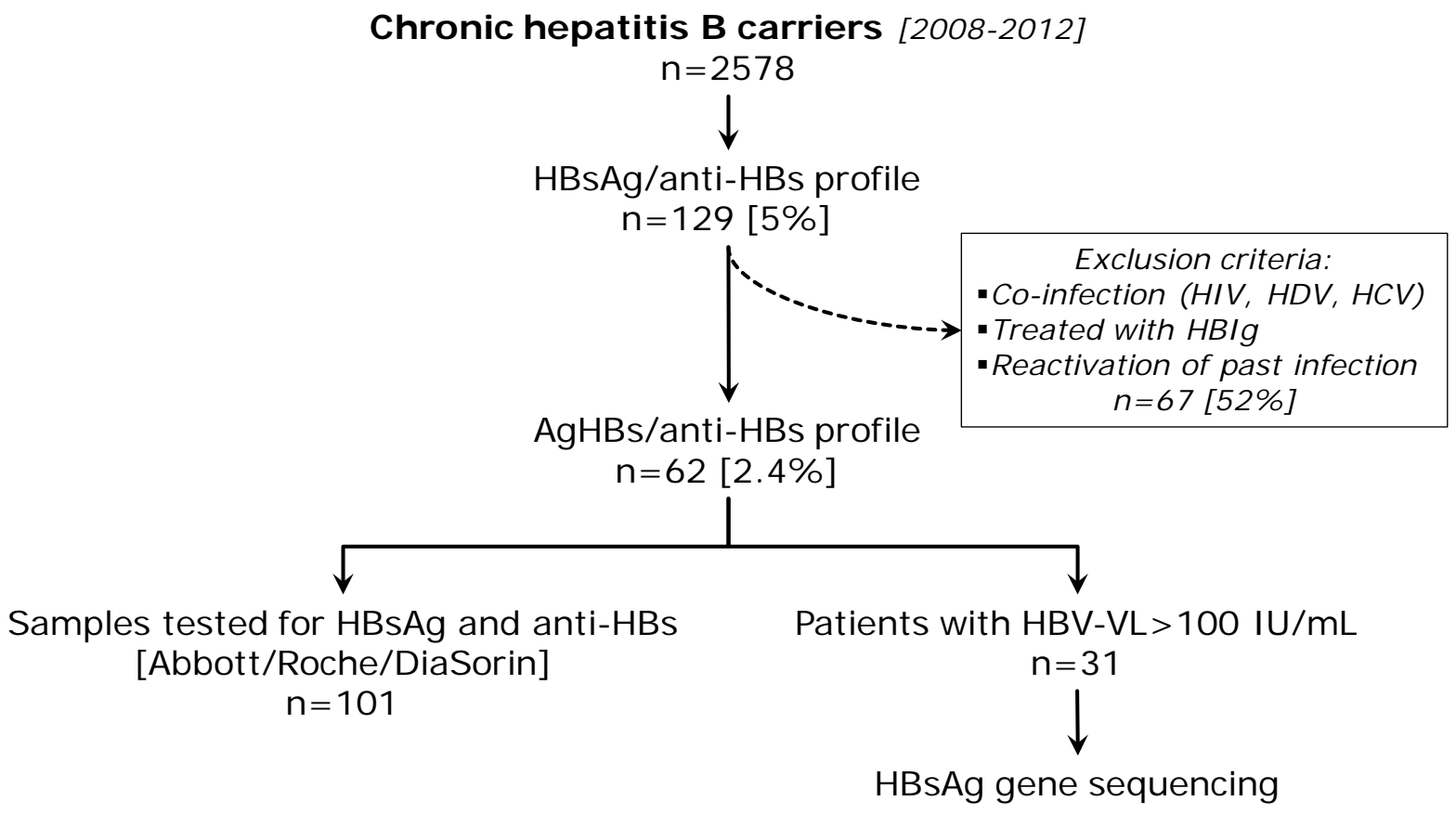


Figure 2
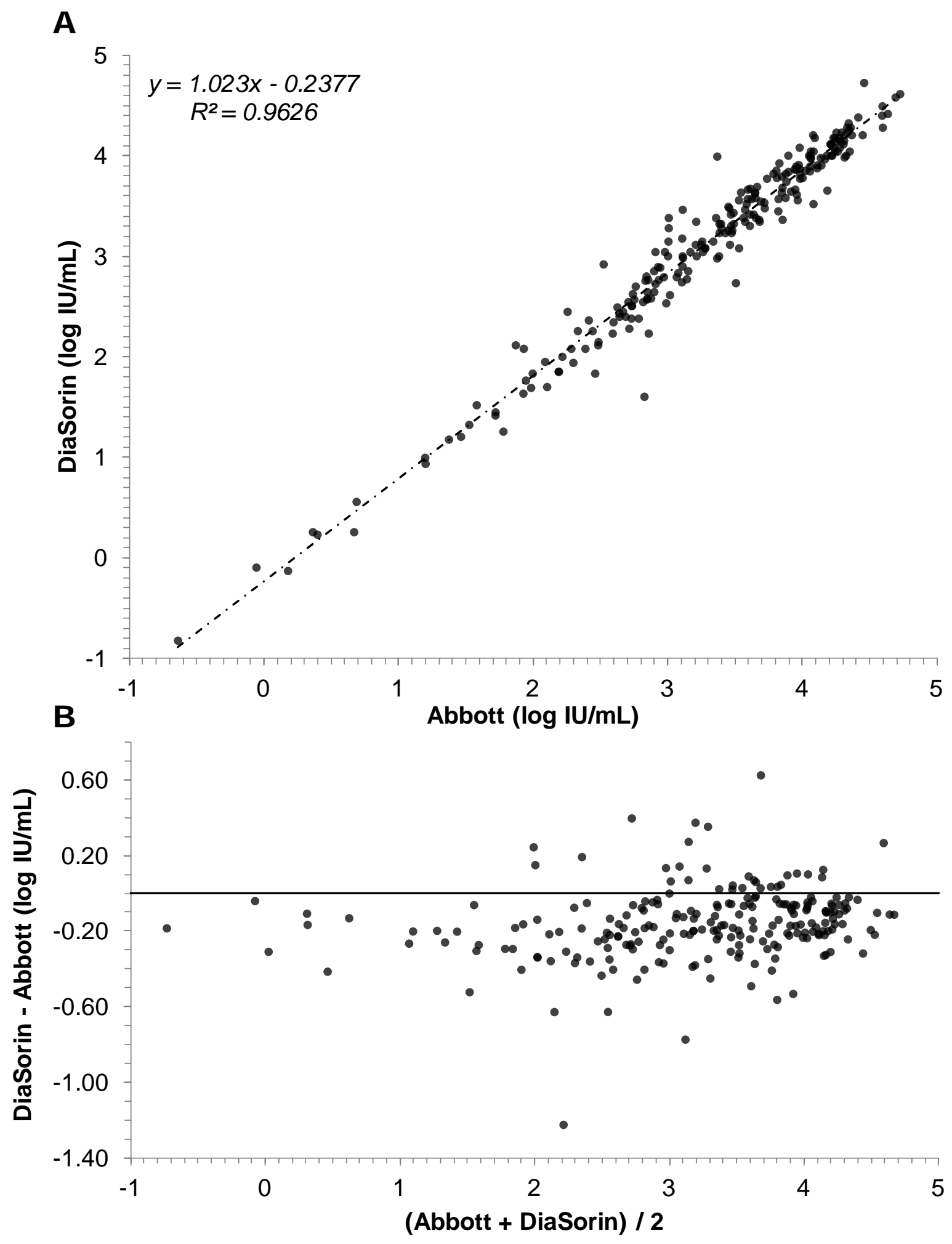
Figure 3 :

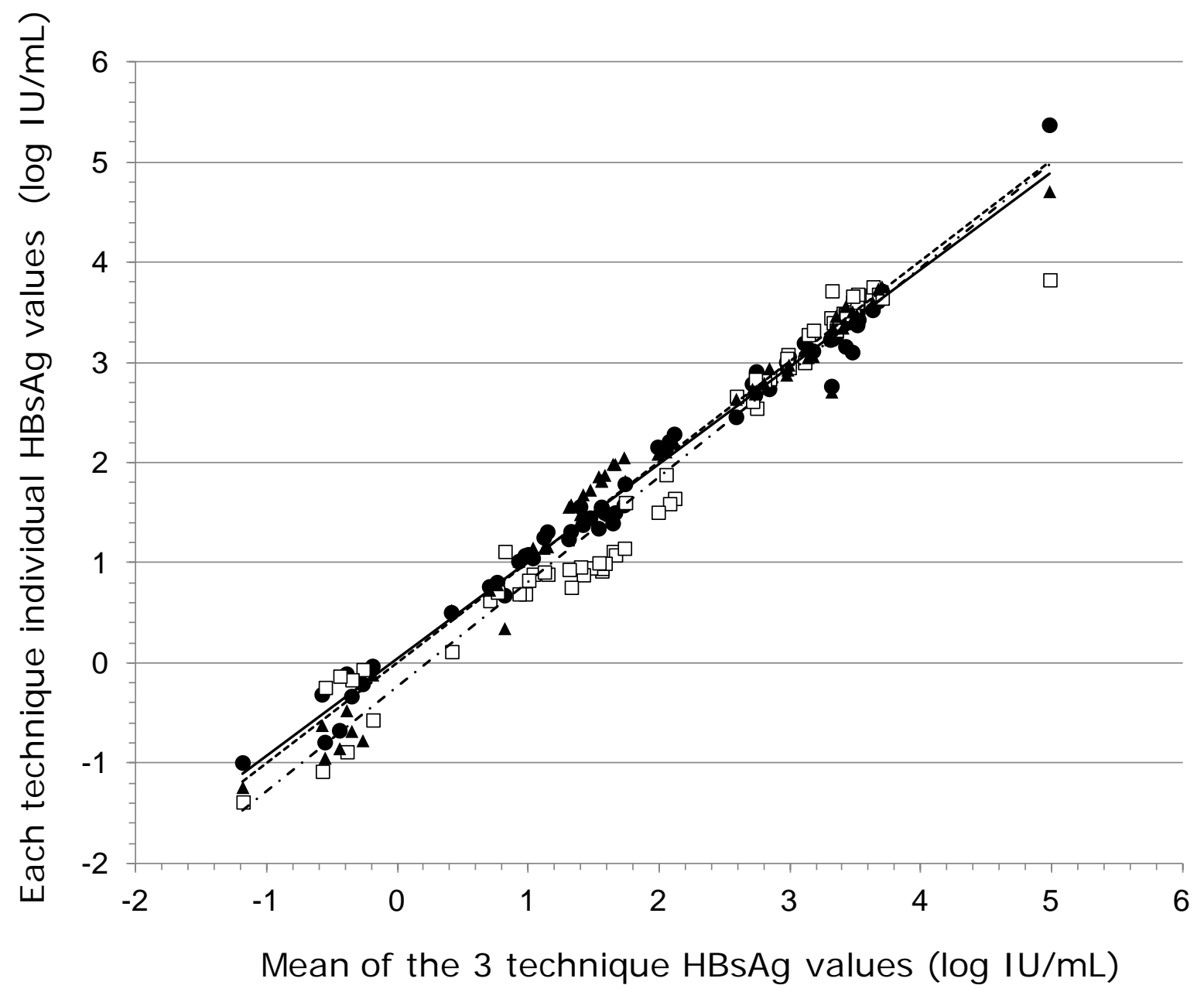


Fig. 4

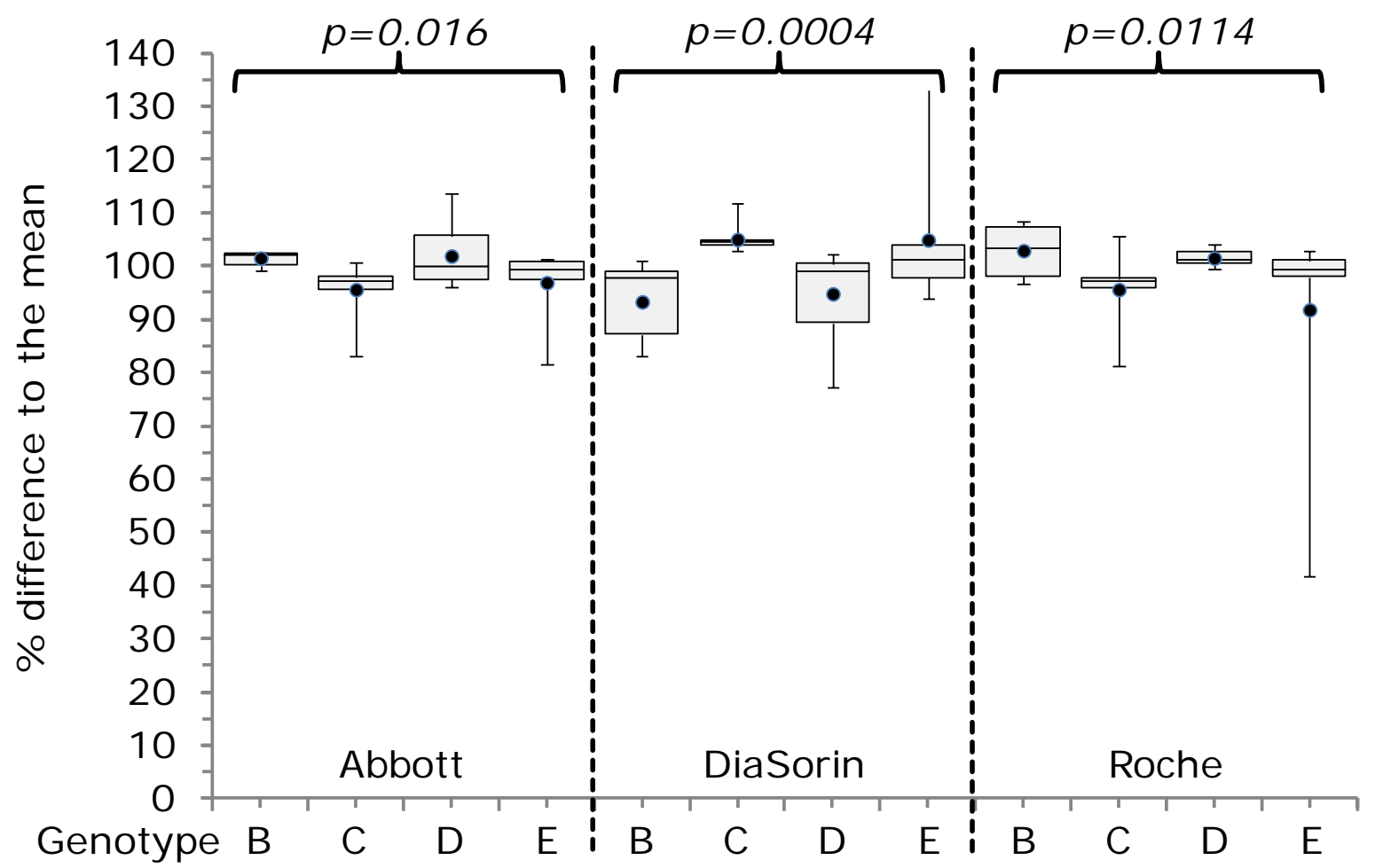


Fig. 5

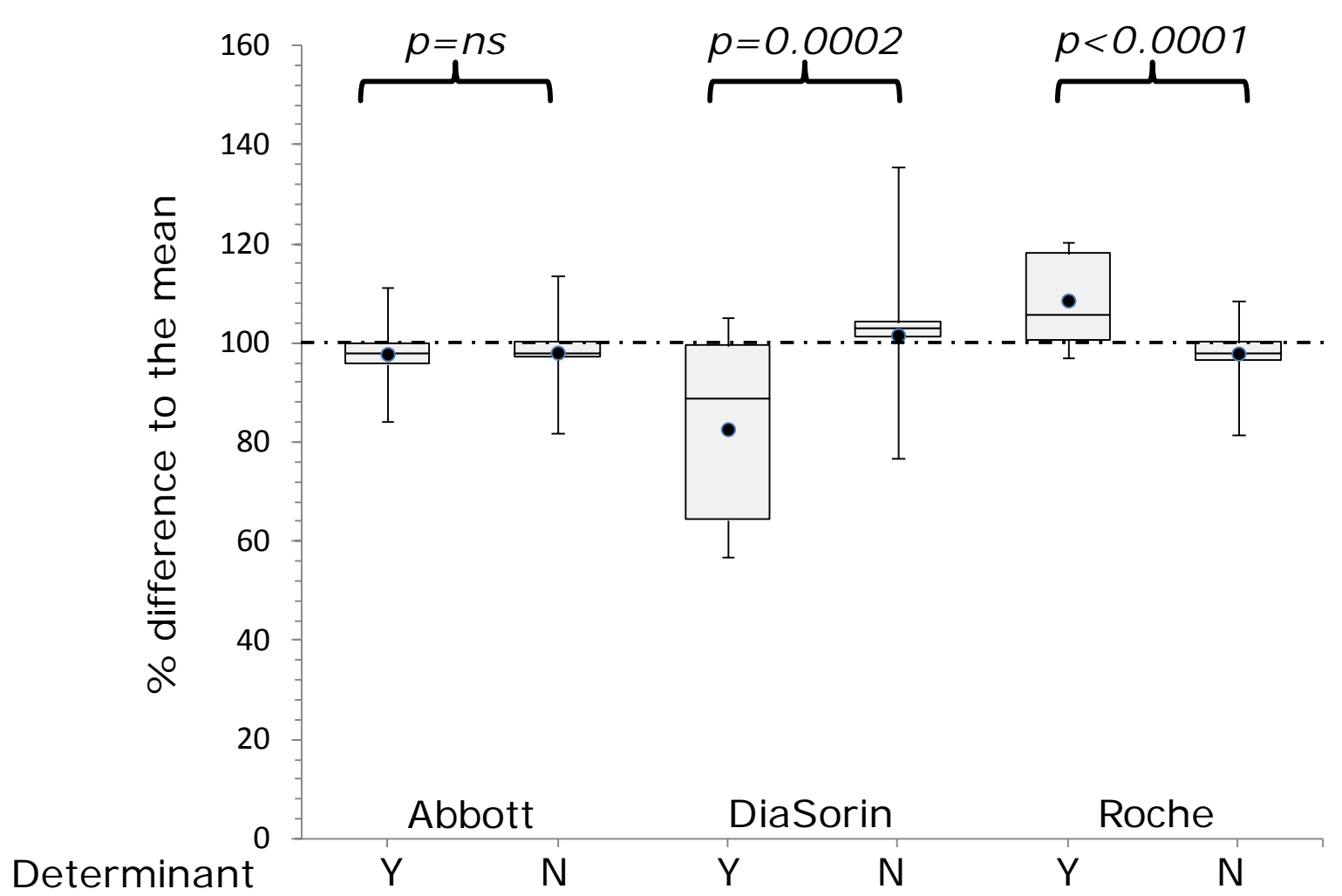
"a" variant 